\title{
An Integrated Approach for the Operational Design of a Cellular Manufacturing System
}

\author{
Ayesha Maroof ${ }^{1}$, Adnan Tariq ${ }^{2}$, Sahar Noor ${ }^{3}$ \\ RECEIVED ON 26.06.2019, ACCEPTED ON 19.05.2020
}

\begin{abstract}
Shorter product life cycles, unpredictable demand patterns and the ever-shrinking time to market, have been constantly keeping the manufacturing firms under a lot of pressure. To face these challenges the manufacturing organizations have been shifting to Cellular Manufacturing (CM) due to its benefits of reducing manufacturing costs, increasing flexibility and delivering orders on time. Despite having several benefits, designing a Cellular Manufacturing System (CMS) for a real-life application is a tough ask. The main challenge is the part-machine grouping in cells. It becomes even more challenging when the group scheduling (GS) problem is handled alongside the part-machine clustering. To take up this challenge, an integrated model is developed during this research which handles the machine-part grouping and the GS problems, simultaneously. To optimize the multiple objectives of maximizing Grouping Efficacy (GE) and minimizing Makespan $\left(\mathrm{C}_{\max }\right)$, concurrently, a Hybrid Genetic Algorithm (HGA) based approach is developed. The proposed technique is validated through the famous benchmark problems, unlike the several approaches already available in literature. The computational results have shown that the integrated approach, presented in this paper, is more effective as compared to a sequential technique. Also, its accuracy remains intact even if it is applied to large sized problems.
\end{abstract}

Keywords: Cellular Manufacturing System, Grouping Efficacy, Makespan, Hybrid Genetic Algorithm

\section{INTRODUCTION}

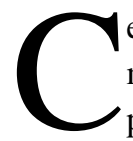
ellular Manufacturing System (CMS) is a manufacturing concept based on the philosophy of Group Technology (GT). It is implemented by arranging the entire manufacturing system into cells, where parts having similar processing requirements are processed inside a single cell. This particular arrangement (identification of part families and corresponding machine groups) of the system makes the production flow simpler and shorter which significantly decreases the lead times and material handling costs. This is the reason that
CMS is largely considered to have the ability of economically producing parts in medium volume and variety as compared to the conventional manufacturing systems. Main cause for the success of CMS is its capacity to reduce: set-up times, work in process, lot sizes, production equipment and enhanced productivity [1]. Cellular Manufacturing (CM) is the approach which is best suited to the present day's competitive market environment where manufacturers consistently strive to increase their efficiency by reducing delivery times and improving product quality without substantially enhancing investments [2]. Despite being hugely beneficial,

${ }^{1}$ Department of Industrial Engineering, Istanbul Ticaret University, Istanbul, Turkey.

Email: ayesha.maroof@istanbulticaret.edu.tr (Corresponding Author).

${ }^{2}$ Department of Mechanical Engineering, Wah Engineering College, University of Wah, Wah Cantt, Pakistan.

Email: adnan.tariq@wecuw.edu.pk

${ }^{3}$ University of Engineering and Technology, Peshawar, Pakistan. Email: sahar@uetpeshawar.edu.pk

This is an open access article published by Mehran University of Engineering and Technology, Jamshoro under CC BY 4.0 International License. 
designing a CMS is a challenging task. Identifying part families and formulating corresponding machine cells is the fundamental problem of CM [3] and generally known as the Cell Formation Problem (CFP). Various approaches have been developed over the years to solve the CFP [4 - 14]. In CM each cell is a distinct manufacturing unit capable of processing a family of parts that is assigned to it and has similar processing and manufacturing requirements $[15,16]$. This similarity is in fact the main reason behind the considerable improvements in the overall productivity of the system.

Though solving CFP has always remained the main essence of designing a CMS, however, issues like production planning, layout generation and machinepart scheduling have also been effectively contributing in enhancing productivity and are, therefore, required to be duly considered while designing a CMS [17]. Though these issues e.g. Group Layout (GL) and Group Scheduling (GS), are very essential, still handling them alongside CFP makes the problem even more computationally intensive [18]. However, keeping its benefits in view, several approaches have been developed to handle these problems either sequentially or in an integrated manner. Nsakanda et al. [8] presented an approach that concurrently handled machine allocation problem, part multiple routing problem and CFP. The model aimed at minimizing the inter and intra cellular costs in addition to the outsourcing costs. To optimize the model, a Hybrid Genetic Algorithm (HGA) based approach was developed and validated through smallsized problems generated/tailored specifically for this approach. Another integrated model, considering the cell configuration and lot sizing problems, was developed by Defersha and Chan [19]. The objective of the model was to minimize the costs of quality enhancement and overall production of the system. Here, also, validation of the model was carried out through data sets specifically generated for this technique. Kioon et al. [20], also, developed an integrated model using a Hierarchical Genetic Algorithm. The computational results of the approach concluded that concurrent approaches design the system more effectively. Here also validation of the approach was carried out through data sets generated precisely for this model.
A mathematically integrated technique was developed by Safaei et al. [21]. It was capable of handling cell formation and layout generation problems, while minimizing fixed and varying costs of processing. This model was also validated through small data sets explicitly generated/tailored for the approach. Rafiee et al. [22] developed a mixed integer linear programming model to handle the operational issues like: operation sequence, lot splitting, duplicate machines, and machine capacity. Due to its complexity, the model was validated through small data sets. They also suggested to use meta-heuristics to solve large scale problems. Though the designed approach considered many design parameters which brought it close to a realistic CMS design, but the model would have been even more effective had it been able to handle larger data sets and properly validated through benchmarks problems.

Chang et al. [23] presented an approach based on Tabu Search for simultaneously considering machine sequence, GL and CFP. Volume of production, sequence of operations and process routings were considered as the design parameters. Like many other approaches, here too, validation was carried out through small-sized problems particularly generated for the approach. The approach developed by Nouri et al. [24] was a realistic multi-objective model that could handle assignments of machines, material handling cost, balancing of workload, assignment of workers and outsourcing. The authors proposed that embedding design related issues such as machine-part sequencing, setup cost, and tooling cost into the model can further enhance its flexibility and can relate it to a real shop floor environment. But, by doing so, the complexity of the model would increase, and validation would then be an issue. An experimental design approach based on GA, for the scheduling of a CMS was presented by Fahmy [25]. In this approach a mixed integer based linear programming approach was adopted to model the GF, GL and GS problems. A limited computational experimentation could be carried out due to complexity of the model. Egilmiz et al. [26] handled the stochastic demand, processing times and capacity using a stochastic GA while designing a CMS. The alternative routing of parts, tool assignment and machine reliability issues were tackled by Khorasgani 
\& Ghaffari [27]. The maximum problem size that they handled was 6 parts and 6 machines. Karoum and Elbani [28] presented an approach handling similar kind of objectives as Khorasgani \& Ghaffari [27]. The authors admitted that integration of more and more operational problems with CFP makes it computationally intensive thus smaller sized problems could only be solved during validation. A GA based approach integrating a number of manufacturing attributes \{e.g., machines reconfiguration, work force adjustment, cost of inter and intra cellular movements etc. \} was presented by Hao et al. [29]. A two-layer GA based approach was presented by Razazadeh \& Miab [30] to reduce manufacturing cost, increase quality of the product and reliability of the system. Due to complexity of the model a limited computational experience, for the validation, was presented. A GA based approach for machine loading in cells with flow-shop configuration was presented by Gannon \& Suer [31]. Hasan et al. [32] developed a similarity coefficientbased approach for hierarchical clustering of parts based on complexity level of individual parts for assembly systems. Tariq et al. [53] developed an operational design of CMS by sequentially handling the CFP and GS problem. Though the approach presented was a realistic one but the use of specific data sets and smaller problem sizes for validation reduced its scope of becoming a generalized approach comparable with other techniques.

The literature review, presented above, discussed a reasonable number of research papers in which multiple objectives (CFP, GL, GS etc.) were handled. Apparently, all these approaches seemed to be very realistic. However, by solving several objectives, their computational effort increased drastically. Therefore, most of the approaches used tailormade small sized data sets, for their validation, rather than the generalized benchmark problems, already available in literature. This has disconnected these modern approaches from the famous benchmark problems thus making the cross comparisons, of different techniques, difficult to carry out as each has been using its own set of problems for verifying its effectiveness. Therefore, having this motivation, an integrated operational approach, for designing a CMS, is developed during this research that can handle CFP and GS problems simultaneously. The approach maximizes Grouping Efficacy (GE) and minimizes Makespan $\left(C_{\max }\right)$, for the same system, concurrently. To prove its effectiveness its results are compared with a sequential approach. The most significant aspect of the proposed model is that its validation and comparison has been carried out through the benchmark problems already reported in literature. Since the processing times and sequence of operations are not available in the benchmark problems, therefore, this part of the data is being randomly generated and in future can be used by other researchers as a benchmark for comparing different techniques. The comparison of computational results has shown that the integrated approach presented during this research is comparatively more effective and helps in reducing the cost of manufacturing.

\section{MODELLING OF THE SYSTEM}

The solution approach, developed during this research, is maximizing GE and minimizing the corresponding $\mathrm{C}_{\max }$. For mathematical modelling of this approach following are some of the assumptions considered:

1. The model is proposed for a static demand of parts and does not cater for the dynamic aspects.

2. Machine capabilities are known, and no machining flexibility has been considered.

3. Each part has a predefined operation sequence as flexible routings have not been considered.

4. For each operation, the processing time is defined/known in advance.

5. Each operation is executed on a distinct machine as jobs are not allowed to revisit a machine.

6. Setup times are included in the processing times and are therefore not shown separately on the Gantt Charts.

\subsection{Nomenclature}

To mathematically formulate the bi-objective model, proposed during this research, some variables and indices are considered and defined as follows:

$\mathrm{P}=$ Total number of parts

$\mathrm{M}=$ Total number of machines Mehran University Research Journal of Engineering and Technology, Vol. 40, No. 2, April 2021 [p-ISSN: 0254-7821, e-ISSN: 2413-7219] 
$\mathrm{NC}=$ Total number of cells

$\mathrm{N} 1_{\text {in }}=$ Total number of operations within cells

$\mathrm{N} 1_{\text {out }}=$ Total number of intercellular moves

$\mathrm{N}_{\mathrm{mp}}=$ Total number of operations (both within cells and intercellular moves)

$\mathrm{k}=1 \ldots \mathrm{NC}$ (Total Number of cells)

$\mathrm{NM}=$ Number of machines in cell $\mathrm{z}$.

$\mathrm{NP}=$ Number of parts in cell $\mathrm{z}$.

$\mathrm{i}=1 \ldots \mathrm{p}$ (Total number of parts)

$\mathrm{j}=1 \ldots \mathrm{m}$ (Total number of machines)

$\mathrm{p}_{\mathrm{ij}}=$ Processing time of part $\mathrm{i}$ on machine $\mathrm{j}$.

$\mathrm{O}_{\mathrm{ij}}=$ Represents processing of part $\mathrm{i}$ on that machin $\mathrm{j}$ which completes processing in the last and hence defines the value of $C_{\max }$

$\mathrm{ST}_{\mathrm{ij}}=$ Start time of part $\mathrm{i}$ on machine $\mathrm{j}$.

$\mathrm{JAT}_{\mathrm{i}}=$ Job availability time of part $\mathrm{i}$

$\mathrm{MAT}_{j}=$ Machine availability time of machine $\mathrm{j}$

$\mathrm{CT}_{\mathrm{ij}}=$ Completion time of part $\mathrm{i}$ on machine $\mathrm{j}$.

$\mathrm{C}_{\max }=$ Makespan

$\mathrm{N}_{\mathrm{mp}}=\sum_{\mathrm{j}=1}^{\mathrm{m}} \sum_{\mathrm{i}=1}^{\mathrm{p}} \mathrm{a}_{\mathrm{ij}} \forall \mathrm{a}_{\mathrm{ij}}=1[10]$

$\mathrm{N} 1_{\mathrm{in}}=\sum_{\mathrm{k}=1}^{\mathrm{NC}} \sum_{\mathrm{j}=1}^{\mathrm{NM}} \sum_{\mathrm{i}=1}^{\mathrm{NP}} \mathrm{a}_{\mathrm{ij}} \forall \mathrm{a}_{\mathrm{ijk}}=1[10]$

$\mathrm{N} 1_{\text {out }}=\mathrm{N}_{\mathrm{mp}}-\mathrm{N} 1_{\text {in }}$

$\mathrm{ST}_{\mathrm{ij}}=\max \left[J A \mathrm{~T}_{\mathrm{j}}, \mathrm{MAT}_{\mathrm{i}}\right]$

$\mathrm{CT}_{\mathrm{ij}}=\mathrm{ST}_{\mathrm{ij}}+\mathrm{p}_{\mathrm{ij}}$

\subsection{Optimization Model}

In order to simultaneously maximize Grouping Efficacy (GE) and minimize Makespan $\left(\mathrm{C}_{\max }\right)$ for a same system the formulation of the objective function and its related constraints is shown as follows:

If:

$\mathrm{A}=$ Cost in \$ per unit of loss in GE

(1\$ per unit loss in GE is considered during this research)

$\mathrm{B}=$ Cost per unit time spent on the shop floor

(waiting or procurement) $=\$ /$ time

(1\$ per unit of time spent on the shop floor is considered here)

Then the cost function can be:

$\mathrm{F}=\operatorname{Minimize}\left[\{100-\mathrm{GE}\} \mathrm{A}+\left\{\mathrm{C}_{\max } \times \mathrm{B}\right\}\right]$

$$
\begin{aligned}
& \mathrm{F}=\text { Minimize }\left[\left\{100-\left(\frac{\mathrm{N}_{\mathrm{mp}}-\mathrm{N} 1_{\text {out }}}{\mathrm{N}_{\mathrm{mp}}+\mathrm{N} 0_{\text {in }}}\right)\right\} \mathrm{A}+\right. \\
& \left.\left\{\mathrm{C}_{\max } \times \mathrm{B}\right\}\right]
\end{aligned}
$$

Makespan $\left(\mathrm{C}_{\max }\right)$ can be calculated by summing up the processing and waiting times of all the jobs getting processed on that machine which finishes processing of jobs in the end, as shown in equation (8)

$\mathrm{C}_{\max }=\sum_{0=1}^{\mathrm{N}}\left(\mathrm{CT}_{0}-\mathrm{ST}_{0}\right)+\sum_{0=1}^{\mathrm{N}-1}\left(\mathrm{ST}_{0+1}-\mathrm{CT}_{0}\right)$

where:

$\sum_{0=1}^{\mathrm{N}}\left(\mathrm{CT}_{0}-\mathrm{ST}_{0}\right)$

represents the processing times of all jobs on the machine that completes its processing in the end.

$\sum_{0=1}^{\mathrm{N}-1}\left(\mathrm{ST}_{0+1}-\mathrm{CT}_{0}\right)$

represents the waiting times in between processing of all the jobs on the machine that finishes its processing in the end.

Subject to:

$2 \leq \mathrm{NC} \leq \mathrm{m}$

$\sum_{\mathrm{k}=0}^{\mathrm{NC}} Z_{k} \geq 1$

$\sum_{\mathrm{i}=0}^{\mathrm{m}} \sum_{\mathrm{i}=0}^{\mathrm{np}} \mathrm{a}_{\mathrm{ij}} \leq \mathrm{M} \times \mathrm{P}$

Constraint (9) ensures that the total number of cells remains within 2 and the total number of machines " $m$ ". Constraint (10) ensures, that there is at least one machine and one part in each cell. Constraint (11) is fulfilling the restriction that each part will visit each machine only once, which generally is the case in classical job shop scheduling problem [53]. There are also some non-negativity constraints as shown in (12), (13) and (14).

$\mathrm{ST}_{\mathrm{ij}} \geq 0$

$\mathrm{JAT} \geq 0$

$\mathrm{MAT} \geq 0$ 


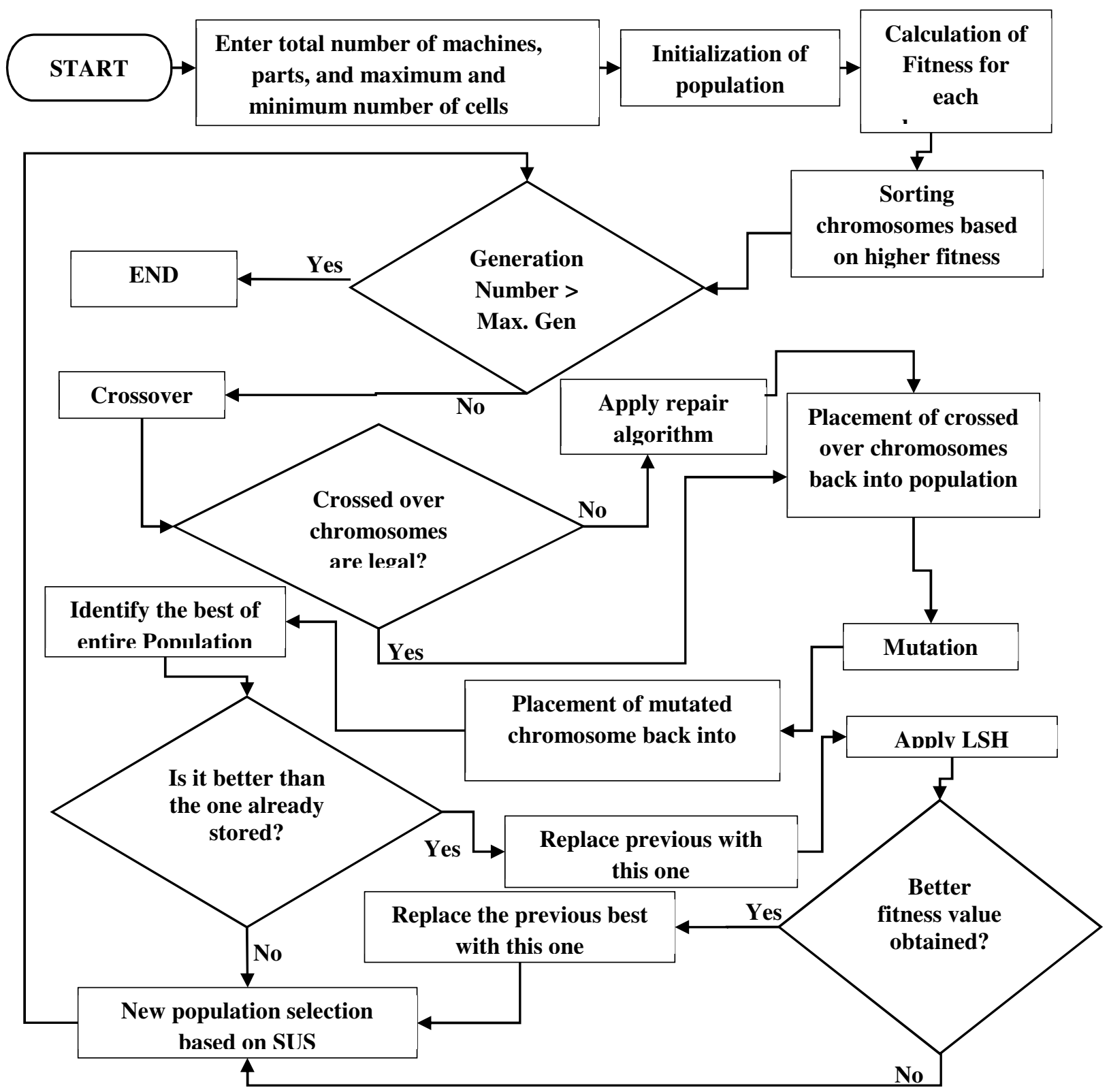

Fig. 1: Hybrid GA Approach

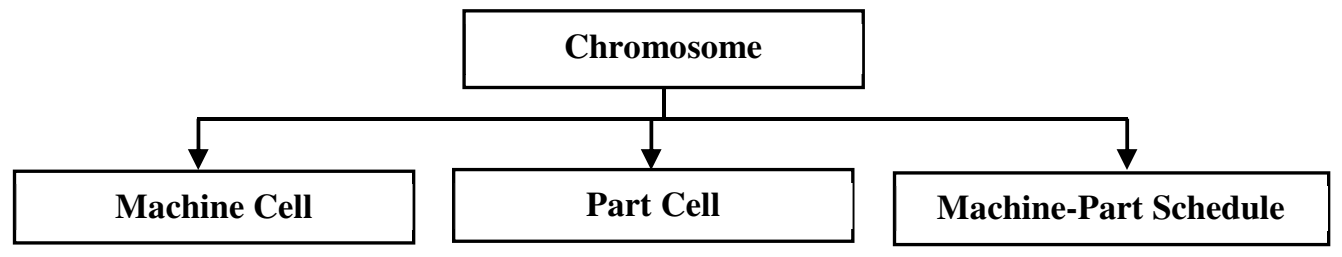

Fig. 2: A Chromosome Subdivision 


\section{HYBRID GA APPROACH}

To validate the mathematical model presented in section 2 a hybrid GA based approach is developed during this research. GA is one of the meta-heuristics that mimics the natural process of selection [52]. The use of GA during this research was purely based on its track record of solving CFPs. Arora [33] described GA as the most effective algorithm applied to CFP. These abilities of GA have become the basis for further development for solving real life CFPs.

Fig. 1 clearly displays a detailed view of the hybrid GA based approach presented in this paper which is actually a combination of standard GA with a local search heuristic. The implementation of this approach requires the following four essential decisions to be taken prior to formally encoding the proposed algorithm:

1. Scheme and type of representation

2. Crossover strategies

3. Mutation strategies

4. Selection criteria

\subsection{Chromosomal Representation}

The first step in the implementation of GA is to devise a strategy for representing a chromosome. An integerbased approach is adopted during this research due to its ability to identify each part and machine with respect to its assigned cell [53]. Also, integers are easy to use while specifying sequences in scheduling problems [53]. Each chromosome contains Information about machines, parts and parts schedule as shown in Fig.2.

Following inputs were required for the generation of each 2-Dimensional (2-D) chromosome in the $1^{\text {st }}$ generation:

1. Number of machines

2. Minimum number of cells

3. Maximum number of cells

4. Maximum Part Incidence Matric (MPIP)

5. Processing Sequence Matrix

6. Processing Time Matrix

To specify the representation scheme, a complete chromosome is displayed in Table 1. The encircled value, in first row and first column, shows the total number of cells. Then, from second column (in first row) onwards till the end of the row (row 1) machine allocation followed by parts allocation to cells, is shown. From the second row, onwards till end of the table, the machine-part sequence is displayed based on operation-based sequencing approach where each integer is represented operations (machines) times' e.g., integer 6 (first in the second row) would be displayed 6 times as there are a total number of 6 machines in this problem. The first 6 would represent operation one of job 6 , similarly the second 6 would represent its second operation and so on. Zeros are added in the end just to fill in the empty spaces and keep the symmetry of the matrix/table intact.

Table 1: 2D Chromosome of a $6 \times 8$ Problem

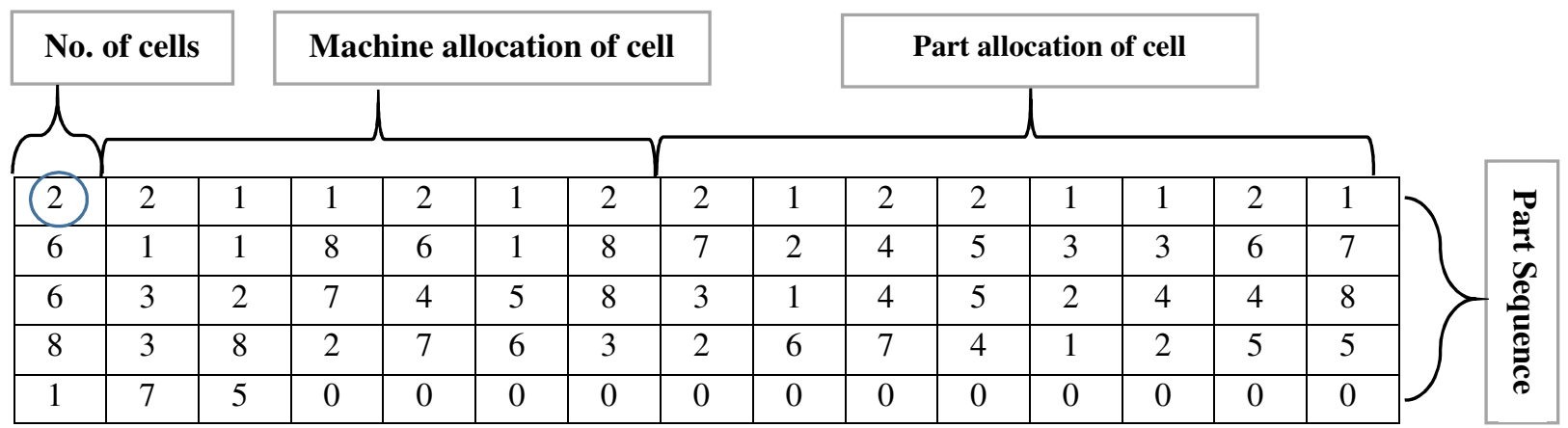




\subsection{Crossover and Mutation Strategies}

In this research, a multi-cut-point crossover has been used while ensuring that exchange of elements only occurs within the same portion e.g., integers in the parts' portion can only be exchanged with other entries in the same portion. As far as mutation is concerned a swap type mutation is used during this research. The main aim of using this type of mutation is to avoid any illegality or infeasibility of the mutated chromosomes [53]. Here also it is ensured that swapping of elements remains limited to their respective portions.

\subsection{Selection Method}

Stochastic Universal Sampling (SUS) is used as the method of selecting future generations from current ones. The main advantage of this approach is that unlike Roulette Wheel method it displays minimum spread and zeros bias towards solutions having higher fitness values [53].

\section{NUMERICAL EXAMPLE}

In order to further elaborate the approach developed during this research a numerical problem of size $7 \times 11$ is selected from Boctor [34]. The Machine-Part Incidence Matrix (MPIM) of the problem and the corresponding, randomly generated, processing sequence and processing times are shown in Tables 2 , 3 and 4, respectively. The best chromosome, for the numerical example, generated by this approach is presented in Table 5 and after being decoded its

\begin{tabular}{|c|c|c|c|c|c|c|c|}
\hline \multicolumn{7}{|c|}{ Table 2: MPIM [26] } \\
\hline & \multicolumn{7}{|c|}{ Machines } \\
\hline Jobs & $\mathbf{1}$ & $\mathbf{2}$ & $\mathbf{3}$ & $\mathbf{4}$ & $\mathbf{5}$ & $\mathbf{6}$ & $\mathbf{7}$ \\
\hline $\mathbf{1}$ & 0 & 1 & 0 & 0 & 0 & 0 & 0 \\
\hline $\mathbf{2}$ & 1 & 1 & 0 & 0 & 0 & 0 & 0 \\
\hline $\mathbf{3}$ & 0 & 0 & 1 & 1 & 1 & 0 & 0 \\
\hline $\mathbf{4}$ & 0 & 0 & 0 & 0 & 1 & 1 & 0 \\
\hline $\mathbf{5}$ & 0 & 0 & 0 & 0 & 0 & 1 & 1 \\
\hline $\mathbf{6}$ & 1 & 1 & 0 & 0 & 0 & 0 & 0 \\
\hline $\mathbf{7}$ & 0 & 0 & 1 & 1 & 0 & 0 & 0 \\
\hline $\mathbf{8}$ & 0 & 0 & 0 & 0 & 0 & 0 & 1 \\
\hline $\mathbf{9}$ & 0 & 1 & 0 & 0 & 0 & 0 & 0 \\
\hline $\mathbf{1 0}$ & 0 & 0 & 0 & 0 & 0 & 1 & 1 \\
\hline $\mathbf{1 1}$ & 0 & 0 & 1 & 0 & 1 & 0 & 0 \\
\hline
\end{tabular}

\begin{tabular}{|c|c|c|c|c|c|c|c|}
\hline \multicolumn{7}{|c|}{ Table 3: Processing Times } \\
\hline & \multicolumn{7}{|c|}{ Machines } \\
\hline Jobs & $\mathbf{1}$ & $\mathbf{2}$ & $\mathbf{3}$ & $\mathbf{4}$ & $\mathbf{5}$ & $\mathbf{6}$ & $\mathbf{7}$ \\
\hline $\mathbf{1}$ & 9 & 0 & 12 & 0 & 0 & 0 & 0 \\
\hline $\mathbf{2}$ & 12 & 14 & 0 & 0 & 0 & 0 & 0 \\
\hline $\mathbf{3}$ & 0 & 0 & 10 & 0 & 11 & 0 & 0 \\
\hline $\mathbf{4}$ & 0 & 0 & 0 & 0 & 6 & 10 & 0 \\
\hline $\mathbf{5}$ & 0 & 0 & 0 & 0 & 0 & 8 & 6 \\
\hline $\mathbf{6}$ & 11 & 9 & 0 & 0 & 0 & 0 & 0 \\
\hline $\mathbf{7}$ & 0 & 0 & 10 & 12 & 0 & 0 & 0 \\
\hline $\mathbf{8}$ & 0 & 0 & 0 & 0 & 0 & 0 & 13 \\
\hline $\mathbf{9}$ & 0 & 12 & 0 & 0 & 0 & 0 & 0 \\
\hline $\mathbf{1 0}$ & 0 & 0 & 0 & 0 & 0 & 7 & 13 \\
\hline $\mathbf{1 1}$ & 0 & 0 & 14 & 0 & 0 & 0 & 0 \\
\hline
\end{tabular}

\begin{tabular}{|c|c|c|c|c|c|c|c|}
\hline \multicolumn{7}{|c|}{ Table 4: Processing Sequence } \\
\hline & \multicolumn{7}{|c|}{ Machines } \\
\hline Jobs & 1 & 2 & 3 & 4 & 5 & 6 & 7 \\
\hline 1 & 2 & 0 & 1 & 0 & 0 & 0 & 0 \\
\hline 2 & 2 & 1 & 0 & 0 & 0 & 0 & 0 \\
\hline 3 & 0 & 0 & 2 & 3 & 1 & 0 & 0 \\
\hline 4 & 0 & 0 & 0 & 0 & 2 & 1 & 0 \\
\hline 5 & 0 & 0 & 0 & 0 & 0 & 2 & 1 \\
\hline 6 & 2 & 1 & 0 & 0 & 0 & 0 & 0 \\
\hline 7 & 0 & 0 & 2 & 1 & 0 & 0 & 0 \\
\hline 8 & 0 & 0 & 0 & 0 & 0 & 0 & 1 \\
\hline 9 & 0 & 1 & 0 & 0 & 0 & 0 & 0 \\
\hline 10 & 0 & 0 & 0 & 0 & 0 & 1 & 2 \\
\hline 11 & 0 & 0 & 1 & 0 & 2 & 0 & 0 \\
\hline
\end{tabular}

corresponding machine-part incidence matrix and Gantt chart representation are displayed in Table 7 and Fig. 3, respectively. To compare this result the best chromosome generated by Zeb et al. [14], for the same problem, is selected and shown in Table 6 . Since Zeb et al. [14] only provided solution for the CFP, therefore, to make it comparable the same data, pertaining to parts' sequencing and processing times (Tables 3 and 4), used by this approach, was also used in case of Zeb et al. [14]. Its block diagonalized machine-part incidence matrix is shown in Table 8 and corresponding Gantt chart representation is presented in Fig. 4.

The best result for CFP, was given by both the 


\begin{tabular}{|c|c|c|c|c|c|c|c|c|c|c|c|c|c|c|c|c|c|c|}
\hline \multicolumn{11}{|c|}{ Table 5: Best Chromosome of $7 \times 11$ Problem (Boctor, 1991 (This Approach) } \\
\hline $\mathbf{4}$ & $\mathbf{1}$ & $\mathbf{1}$ & $\mathbf{2}$ & $\mathbf{2}$ & $\mathbf{3}$ & $\mathbf{4}$ & $\mathbf{4}$ & $\mathbf{1}$ & $\mathbf{1}$ & $\mathbf{2}$ & $\mathbf{3}$ & $\mathbf{4}$ & $\mathbf{1}$ & $\mathbf{2}$ & $\mathbf{4}$ & $\mathbf{1}$ & $\mathbf{4}$ & $\mathbf{3}$ \\
\hline $\mathbf{2}$ & $\mathbf{7}$ & $\mathbf{1 1}$ & $\mathbf{3}$ & $\mathbf{4}$ & $\mathbf{7}$ & $\mathbf{1}$ & $\mathbf{1 0}$ & $\mathbf{9}$ & $\mathbf{9}$ & $\mathbf{2}$ & $\mathbf{2}$ & $\mathbf{7}$ & $\mathbf{1 1}$ & $\mathbf{3}$ & $\mathbf{4}$ & $\mathbf{7}$ & $\mathbf{1}$ & $\mathbf{1 0}$ \\
\hline $\mathbf{9}$ & $\mathbf{9}$ & $\mathbf{2}$ & $\mathbf{2}$ & $\mathbf{2}$ & $\mathbf{2}$ & $\mathbf{7}$ & $\mathbf{1 1}$ & $\mathbf{3}$ & $\mathbf{4}$ & $\mathbf{7}$ & $\mathbf{1}$ & $\mathbf{1 0}$ & $\mathbf{9}$ & $\mathbf{9}$ & $\mathbf{8}$ & $\mathbf{1 0}$ & $\mathbf{1}$ & $\mathbf{8}$ \\
\hline $\mathbf{1 0}$ & $\mathbf{7}$ & $\mathbf{1 1}$ & $\mathbf{3}$ & $\mathbf{4}$ & $\mathbf{1 1}$ & $\mathbf{3}$ & $\mathbf{4}$ & $\mathbf{1}$ & $\mathbf{1 0}$ & $\mathbf{9}$ & $\mathbf{8}$ & $\mathbf{1 0}$ & $\mathbf{1}$ & $\mathbf{8}$ & $\mathbf{3}$ & $\mathbf{6}$ & $\mathbf{6}$ & $\mathbf{1}$ \\
\hline $\mathbf{3}$ & $\mathbf{6}$ & $\mathbf{4}$ & $\mathbf{1 1}$ & $\mathbf{4}$ & $\mathbf{1 1}$ & $\mathbf{8}$ & $\mathbf{5}$ & $\mathbf{8}$ & $\mathbf{8}$ & $\mathbf{6}$ & $\mathbf{6}$ & $\mathbf{6}$ & $\mathbf{6}$ & $\mathbf{5}$ & $\mathbf{5}$ & $\mathbf{5}$ & $\mathbf{5}$ & $\mathbf{5}$ \\
\hline $\mathbf{5}$ & $\mathbf{0}$ & $\mathbf{0}$ & $\mathbf{0}$ & $\mathbf{0}$ & $\mathbf{0}$ & $\mathbf{0}$ & $\mathbf{0}$ & $\mathbf{0}$ & $\mathbf{0}$ & $\mathbf{0}$ & $\mathbf{0}$ & $\mathbf{0}$ & $\mathbf{0}$ & $\mathbf{0}$ & $\mathbf{0}$ & $\mathbf{0}$ & $\mathbf{0}$ & $\mathbf{0}$ \\
\hline
\end{tabular}

\begin{tabular}{|l|l|l|r|r|r|r|r|r|r|r|r|r|r|r|r|r|r|r|}
\hline \multicolumn{11}{|c|}{ Table 6: Best Chromosome of $7 \times 11$ Problem (Boctor, 1991 ) (Zeb et al. (2016)'s Approach) } \\
\hline $\mathbf{4}$ & $\mathbf{1}$ & $\mathbf{1}$ & $\mathbf{2}$ & $\mathbf{2}$ & $\mathbf{4}$ & $\mathbf{3}$ & $\mathbf{3}$ & $\mathbf{2}$ & $\mathbf{1}$ & $\mathbf{2}$ & $\mathbf{4}$ & $\mathbf{3}$ & $\mathbf{1}$ & $\mathbf{2}$ & $\mathbf{3}$ & $\mathbf{1}$ & $\mathbf{3}$ & $\mathbf{4}$ \\
\hline
\end{tabular}

\begin{tabular}{|c|c|c|c|c|c|c|c|}
\hline \multicolumn{7}{|c|}{ Table 7: Integrated Approach } \\
\hline & 1 & 2 & 3 & 4 & 5 & 6 & 7 \\
\hline 1 & 1 & 0 & 1 & 0 & 0 & 0 & 0 \\
\hline 2 & 1 & 1 & 0 & 0 & 0 & 0 & 0 \\
\hline 6 & 1 & 1 & 0 & 0 & 0 & 0 & 0 \\
\hline 9 & 0 & 1 & 0 & 0 & 0 & 0 & 0 \\
\hline 3 & 0 & 0 & 1 & 1 & 1 & 0 & 0 \\
\hline 7 & 0 & 0 & 1 & 1 & 0 & 0 & 0 \\
\hline 4 & 0 & 0 & 0 & 0 & 1 & 1 & 0 \\
\hline 11 & 0 & 0 & 1 & 0 & 1 & 0 & 0 \\
\hline 5 & 0 & 0 & 0 & 0 & 0 & 1 & 1 \\
\hline 8 & 0 & 0 & 0 & 0 & 0 & 0 & 1 \\
\hline 10 & 0 & 0 & 0 & 0 & 0 & 1 & 1 \\
\hline
\end{tabular}

\begin{tabular}{|c|c|c|c|c|c|c|c|c|}
\hline \multicolumn{10}{|c|}{ Table 8: Zeb et al.'s [14] Approach } \\
\hline & & 1 & 2 & 3 & 4 & 6 & 7 & 5 \\
\hline 2 & & 1 & 1 & 0 & 0 & 0 & 0 & 0 \\
\hline 6 & & 1 & 1 & 0 & 0 & 0 & 0 & 0 \\
\hline 9 & & 0 & 1 & 0 & 0 & 0 & 0 & 0 \\
\hline 1 & & 1 & 0 & 1 & 0 & 0 & 0 & 0 \\
\hline 3 & & 0 & 0 & 1 & 1 & 0 & 0 & 0 \\
\hline 7 & & 0 & 0 & 1 & 1 & 1 & 0 & 0 \\
\hline 5 & & 0 & 0 & 0 & 0 & 1 & 1 & 0 \\
\hline 8 & & 0 & 0 & 0 & 0 & 0 & 1 & 0 \\
\hline & & & & & & & & \\
\hline 10 & & 0 & 0 & 0 & 0 & 1 & 1 & 0 \\
\hline 4 & & 0 & 0 & 0 & 0 & 1 & 0 & 1 \\
\hline 11 & & 0 & 0 & 1 & 0 & 0 & 0 & 1 \\
\hline
\end{tabular}

techniques at a total number of cells equal to 4 thus lowing only three intercellular moves. This shows that both techniques are at par as far as solving the CFP is concerned. The difference between the two techniques, however, emerges when solution for scheduling part of the problem is assessed. Here the approach presented in this paper takes the lead as it returns a $C_{\max }$ value of 179 in comparison to 202 by Zeb et al. [14], as shown in Figs. 3 and 4 respectively.
This difference is because of the fact that this approach handles both scheduling and cell formation simultaneously thus creating a possibility of arranging parts and machines into cells in such a way that they would result in smaller $C_{\max }$ values.

Since Zeb et al.[14], is only a CFP solving approach and did not consider the scheduling part of the problem, therefore it returned a larger value of $C_{\max }$ and hence provided strength to the initial idea of this research i.e. integrated approach is better than the sequential approaches.

\section{RESULTS AND DISCUSSION}

Ever since the focus of researchers has shifted from solving CFP to handling operational designs, validation of results and comparison with other relevant techniques has become a difficult task. The main reason is that every author has developed his own set of problems to validate his proposed technique. This has caused a situation where generic benchmark problems (posing operational challenges in addition to $\mathrm{CF}$ ) could not evolve, thus cross comparisons of different approaches have become impossible. To overcome this difficulty and at the same time carrying out comparison, based on the classical benchmark problems, a recently developed approach has been selected. Since the approach selected is only a CFP solving approach therefore to make the comparison more logical its final solutions (machine-part matrices) are provided with the same operational data (parts' processing times and sequences) as used by this approach. The results obtained are tabulated in Table 9. 


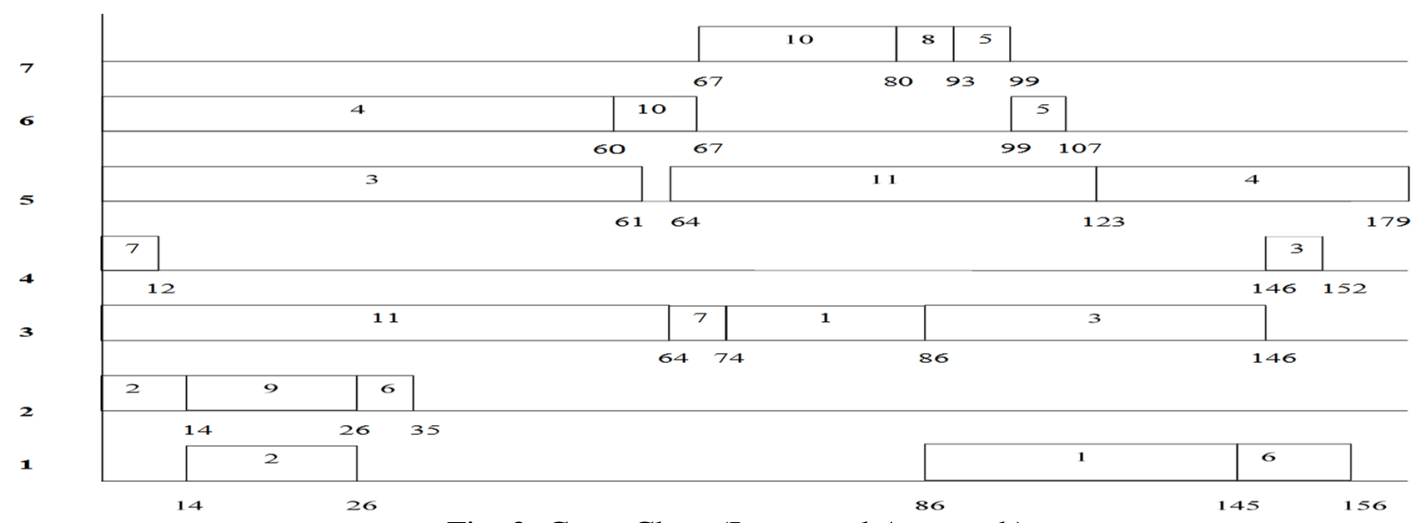

Fig. 3: Gantt Chart (Integrated Approach)

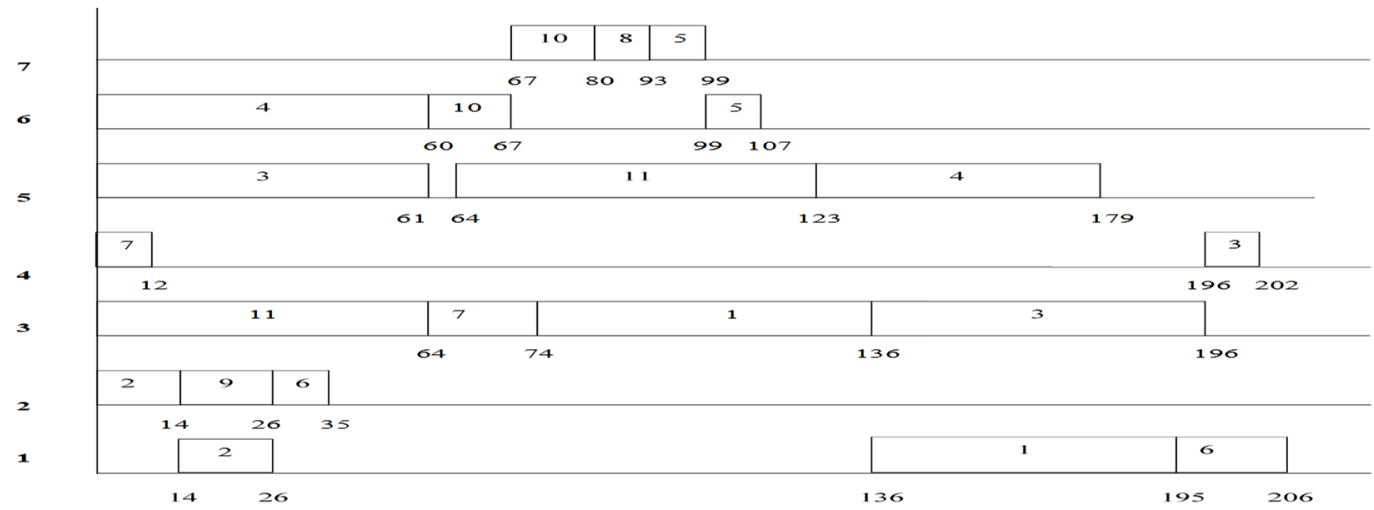

Fig. 4: Gantt Chart (Zeb et al.[14])

A total number of 25 benchmark problems from literature were solved and, for validation, the results have been compared with Zeb et al.[14]. All the results presented in Table 9 can be categorized in three groups. Group 1 comprises of those results in which the values of both GE and $C_{\max }$ are the same. In this group there are a total of $13(52 \%)$ problems. Group 2, on the other hand, consists of those problems in which the values of GE are the same but improvement in terms of $C_{\max }$ has been observed. This group comprises of only $3(12 \%)$ problems (Prob \# 7, 15 and 18). The last group is group 3, which consists of a total number of $8(32 \%)$ problems (Prob \# 13, 14, 16, 17, 19, 20, 21 and 25). The significance of this group is that in terms of GE the results have deteriorated as compared to Zeb et al. [14], but $C_{\max }$ values improved substantially.

To elaborate the results further, a comparison-based $n$ GE, $C_{\max }$ and cost (combined effect of GE and $C_{\max }$ ) is shown in Fig. 5, 6, 7 and 8. The most significant Mehran University Research Journal of Engineering and Technology, Vol. 40, No. 2, April 2021 [p-ISSN: 0254-7821, e-ISSN: 2413-7219] are Fig. 7 and 8 where the combined effect of cost incurred due to loss in GE and increase in $\mathrm{C}_{\max }$ has been displayed. It can be evidently observed in Fig. 7 and Table 9 (highlighted rows) that in 12 problems $(48 \%)$ the total cost incurred in this research is smaller than Zeb et al. [14]. This clearly proves that since the integrated approach, presented in this research, simultaneously maximizes $\mathrm{GE}$ and minimizes $\mathrm{C}_{\max }$ that's why it can effectively minimize the overall cost in comparison to Zeb et al. [14], where this process has been carried out sequentially. Another significance of Fig.7 is that the reduction in cost is mainly observed in the later half of the problems' set i.e., from 13 to 25 (encircled results) where the problem size (MPIM) is larger as compared to the first half. This shows the consistency of this approach as its performance remains stable whereas the results of Zeb et al. [14], deteriorates as the problem size grows. This trend can also be witnessed in Fig. 8. 


\begin{tabular}{|c|c|c|c|c|c|c|c|c|c|}
\hline \multirow[t]{2}{*}{ S.No. } & \multirow[t]{2}{*}{ Source } & \multirow[t]{2}{*}{ Prob size } & \multicolumn{3}{|c|}{ Zeb et al., [14] } & \multicolumn{3}{|c|}{ This Approach } & \multirow{2}{*}{$\begin{array}{l}\% \text { Cost } \\
\text { Saved }\end{array}$} \\
\hline & & & GE & $\mathrm{C}_{\max }$ & Cost $(\$)$ & GE & $\mathrm{C}_{\max }$ & Cost (\$) & \\
\hline 1. & (King \& Nakornchai, 1982) [35] & $5 \times 7$ & 75 & 197 & 122 & 75 & 197 & 122 & 0 \\
\hline 2. & (King \& Nakornchai, 1982) [35] & $5 \times 7$ & 82.35 & 63 & 80.65 & 82.35 & 63 & 80.65 & 0 \\
\hline 3. & (Waghodekar \& Sahu, 1984) [36] & $5 \times 7$ & 69.57 & 230 & 260.43 & 69.56 & 230 & 260.43 & 0 \\
\hline 4. & (Seifoddini, 1989) [37] & $5 \times 18$ & 79.59 & 522 & 542.41 & 79.59 & 522 & 542.41 & 0 \\
\hline 5. & (Kusiak \& Chow, 1992) [38] & $6 \times 8$ & 76.92 & 219 & 242.08 & 76.92 & 219 & 242.08 & 0 \\
\hline 6. & (Kusiak \& Cho,1987) [39] & $7 \times 11$ & 60.87 & 315 & 354.13 & 60.87 & 315 & 354.13 & 0 \\
\hline 7. & (Boctor, 1991) [34] & $7 \times 11$ & 70.83 & 206 & 231.17 & 70.83 & 179 & 208.17 & 9.95 \\
\hline 8. & (Seifoddini, 1989) [37] & $8 \times 12$ & 69.44 & 340 & 370.56 & 69.44 & 340 & 370.56 & 0 \\
\hline 9. & Chandrasekharan \& Rajagopalan,) (1986a) [40] & $8 \times 20$ & 85.25 & 287 & 301.75 & 85.25 & 287 & 301.75 & 0 \\
\hline 10. & Chandrasekharan \& Rajagopalan, 1986b)[40] & $8 \times 20$ & 58.72 & 465 & 506.28 & 58.72 & 465 & 506.28 & 0 \\
\hline 11. & (Mosier \& Taube, 1985a) [41] & $10 \times 10$ & 75 & 184 & 209 & 75 & 184 & 209 & 0 \\
\hline 12. & (Chan \&Milner, 1982) [42] & $10 \times 15$ & 92 & 73 & 81 & 92 & 73 & 81 & 0 \\
\hline 13. & (Askin \& Subramantan,1987) [43] & $14 \times 23$ & 72.06 & 439 & 466.94 & 70.76 & 365 & 394.24 & 15.57 \\
\hline 14. & (Stanfel,1985 [44] & $14 \times 24$ & 70.83 & 562 & 591.17 & 67.65 & 255 & 287.35 & 51.39 \\
\hline 15. & (McCormick et al. ,1972) [45] & $16 \times 24$ & 52.69 & 650 & 697.31 & 52.69 & 600 & 647.31 & 7.17 \\
\hline 16. & Srinivasan et al. (1990) [46] & $16 \times 30$ & 68.99 & 607 & 638.01 & 68.15 & 427 & 458.85 & 28.08 \\
\hline 17. & (King,1980) [47] & $16 \times 43$ & 57.53 & 1162 & 1204.47 & 51.76 & 1005 & 1053.23 & 12.56 \\
\hline 18. & (Mosier \& Taube, 1985b) [41] & $20 \times 20$ & 43.45 & 682 & 738.55 & 43.45 & 559 & 615.55 & 16.65 \\
\hline 19. & (Kumar et al.,1986)[48] & $20 \times 23$ & 50.81 & 682 & 731.19 & 48.02 & 615 & 666.98 & 8.78 \\
\hline 20. & (Carrie, 1973) [49] & $20 \times 35$ & 78.4 & 247 & 268.6 & 76.13 & 173 & 196.87 & 26.71 \\
\hline 21. & (Boe \& Cheng, 1991)[50] & $20 \times 35$ & 58.38 & 884 & 925.62 & 57.36 & 873 & 915.64 & 1.08 \\
\hline 22. & (Chandrasekharan \& Rajagopalan, 1989)[51] & $24 \times 40$ & 100 & 95 & 95 & 100 & 72 & 72 & 24.21 \\
\hline 23. & (Chandrasekharan \& Rajagopalan, 1989)[51] & $24 \times 40$ & 85.11 & 218 & 232.89 & 85.11 & 218 & 232.89 & 0 \\
\hline 24. & (Chandrasekharan \& Rajagopalan, 1989) [51] & $24 \times 40$ & 73.51 & 315 & 341.49 & 73.51 & 315 & 341.49 & 0 \\
\hline 25. & (Chandrasekharan \& Rajagopalan, 1989) [51] & $24 \times 40$ & 53.29 & 548 & 594.71 & 41.93 & 498 & 556.07 & 6.5 \\
\hline
\end{tabular}

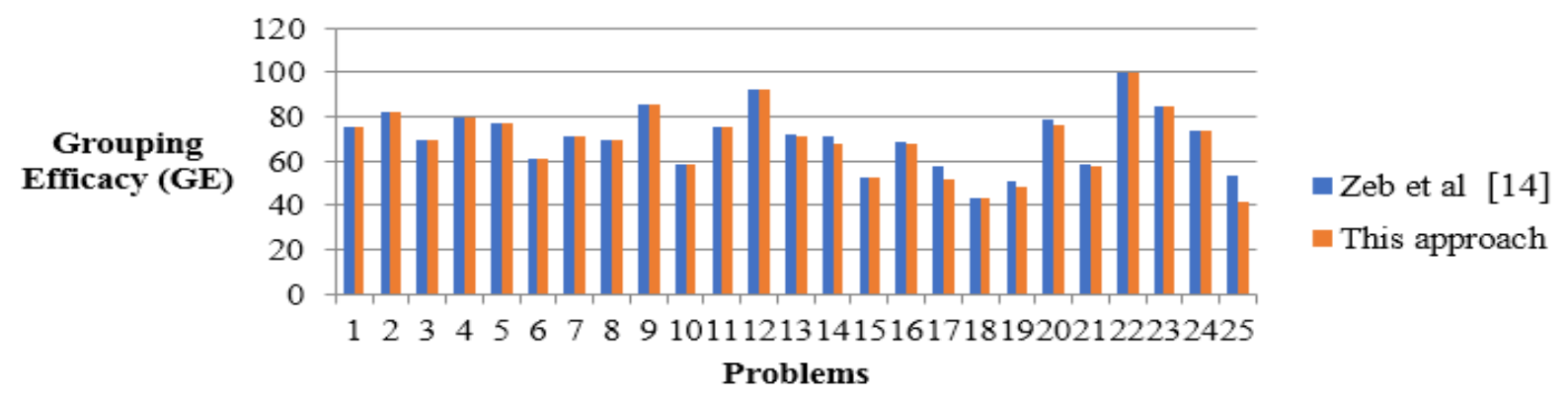

Fig. 5: Comparison in terms of GE

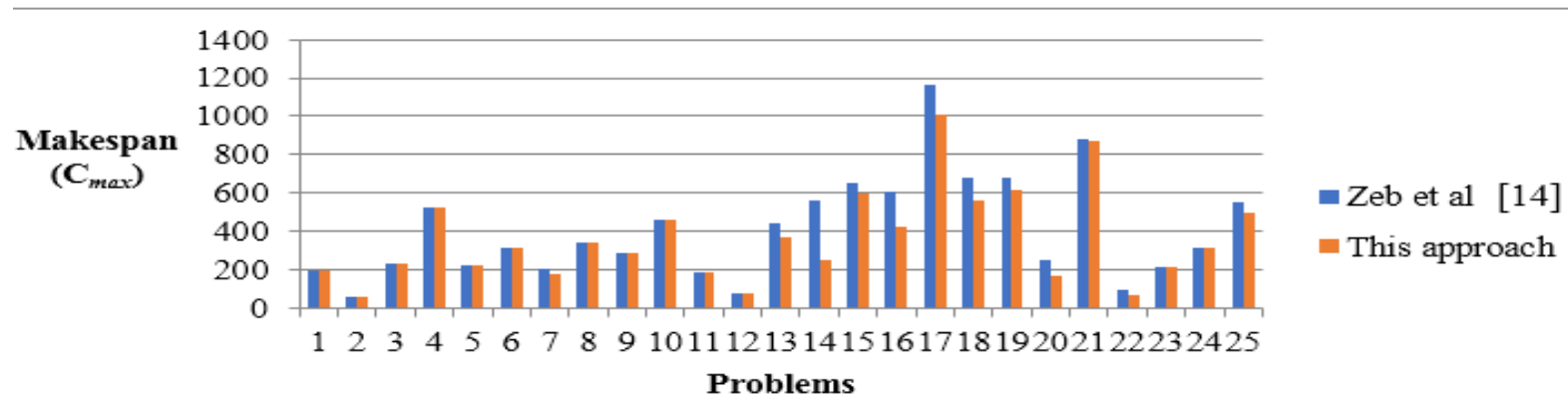

Fig. 6: Comparison in terms of $\mathrm{C}_{\mathrm{MAX}}$ 


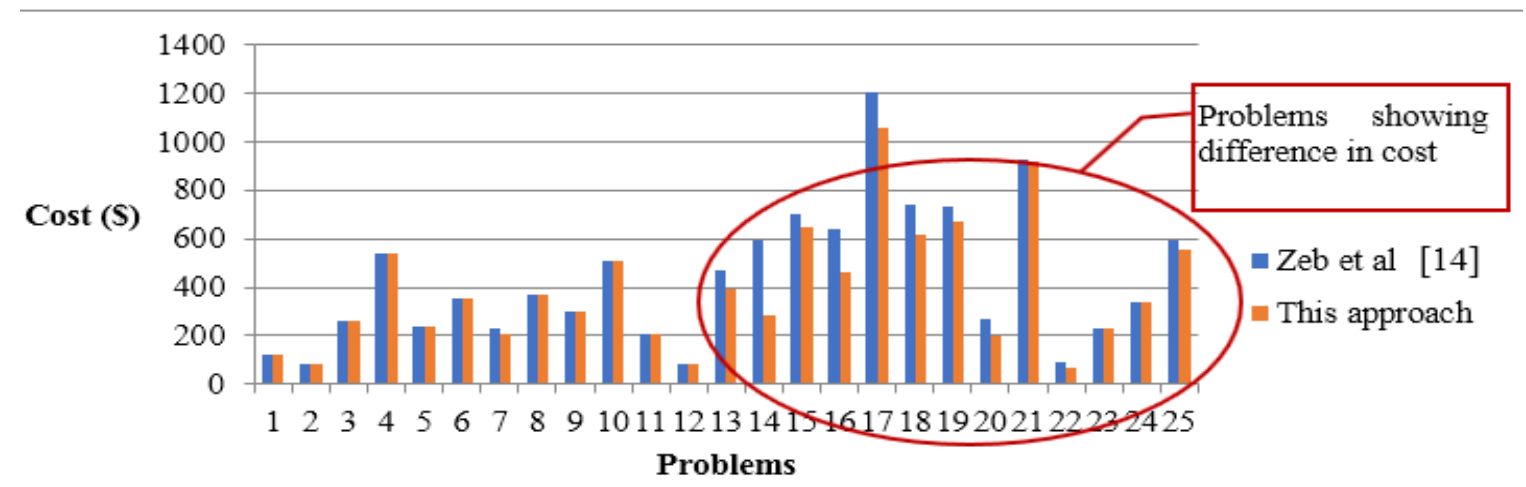

Fig. 7: Comparison in terms of Cost $(\$)$

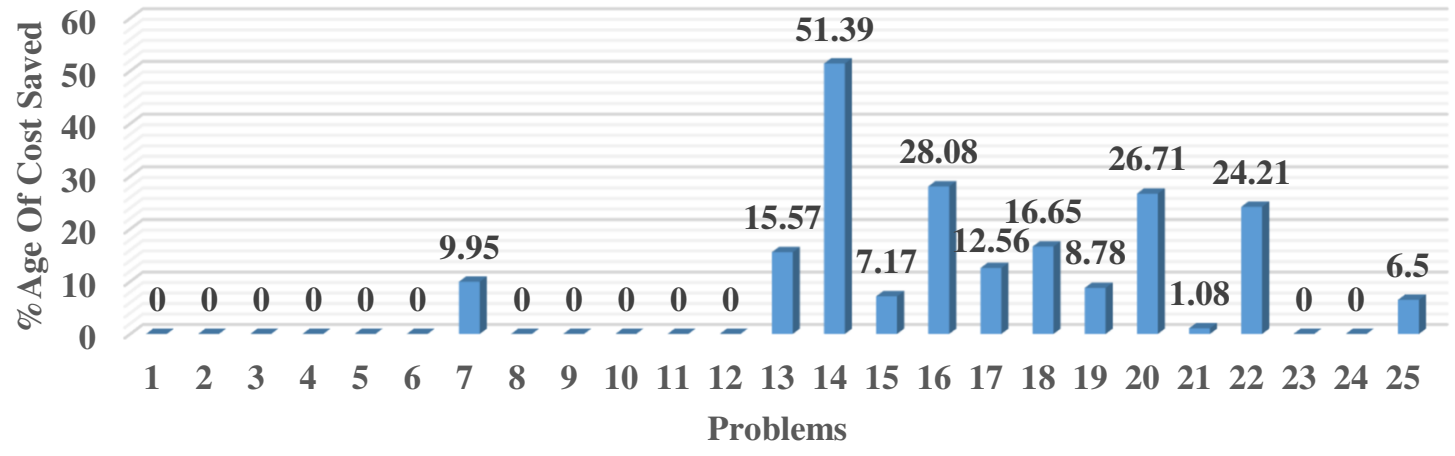

Fig. 8: Percentage of Cost Saved

\section{CONCLUSION}

An integrated operational design for a CMS has been developed, using a hybrid GA, during this research. The approach, being an integrated one, simultaneously maximizes GE and minimizes $\mathrm{C}_{\max }$. To validate the approach a total number of 25 benchmark CFPs were solved using randomly generated operational data (processing times and sequence of operations). The results generated were compared with a recently published approach [14]. Since Zeb et al. [14] only solved CFP and did not calculate $\mathrm{C}_{\max }$, therefore to make the comparison fair and more logical the final solutions of Zeb et al. [14], were provided with the same operational data, that was used during this research, to calculate the values of $\mathrm{C}_{\max }$. By doing this Zeb et al. [14], has been converted into a sequential approach solving CFP first and then using its final outcome (CFP solution) to calculate the value of $\mathrm{C}_{\max }$. The comparison of the results shows that the integrated approach, developed during this research, has effectively outperformed [14], especially in terms of total cost incurred (combined effect of $\mathrm{GE} \& \mathrm{C}_{\mathrm{max}}$,) thus proving the point that integrated approaches can be more effective than the sequential approaches.

\section{ACKNOWLEDGEMENT}

This research work has not been financially supported by any institution/ university. However, the authors acknowledge the general support offered by the University of Wah in completion of this research work.

\section{REFERENCES}

1. Askin R., Standridge C., "Modeling and Analysis of Manufacturing Systems", Wiley, The University of Michigan, 1993.

2. Rezaian J., Javadian N., Tavakkoli-Maghaddam R., Jolai F., "A Hybrid Multi-Objective 
Approach Based on the Genetic Algorithm and Neural Network to Design an Incremental Cellular Manufacturing Systems", Applied Soft Computing, Vol. 11, No.6, pp. 4195-4202, 2011.

3. Soto R., Kjellerstrand H., Duran O., Crawford B. Monfroy E. Paredes F., "Cell Formation in Group Technology Using Constraint Programming and Boolean Satisfiability", Expert Systems with Applications, Vol. 39, No. 13, pp. 11423-11427, 2012.

4. Heragu S. S. "Group Technology and Cellular Manufacturing", IEEE Transactions on System, Man, Cybernetics, Vol. 24, No. 2, pp. 203-215, 1994.

5. Yasuda K., Yin Y., "Dissimilarity Measure for Solving the Cell Formation Problem in Cellular Manufacturing", Computer and Industrial Engineering, Vol. 39, No. 1-2, pp. 1-17, 2001.

6. Onwubolu G.C., Mutingi M., "A Genetic Algorithm Approach to Cellular Manufacturing Systems", Computer and Industrial Engineering, Vol. 39, No.1-2, pp. 125-144, 2001.

7. Uddin M. K., Shanker K., "Grouping of Parts and Machines in Presence of Alternative Process Routes by Genetic Algorithm", International Journal of Production Economics, Vol. 76, No. 3, pp. 219-228, 2002.

8. Nsakanda A. L., Diaby M., Price W. L., "Hybrid Genetic Approach for Solving Large-Scale Capacitated Cell Formation Problems with Multiple Routings", European Journal of Operations Research, Vol. 171, No. 3, pp. 10511070, 2006.

9. Jeon G., Leep H. R., "Forming Part Families by using Genetic Algorithm and Designing Machine Cells under Demand Changes", Computers and Operations Research, Vol. 33, No. 1, pp. 263283, 2006.

10. Tariq A., Hussain I., Ghafoor A., "A Hybrid Genetic Algorithm for Machine-Part Grouping", Computers and Industrial Engineering, Vol. 56, No. 1, pp. 347-356, 2009.

11. Bajestani M. A., Rabbani M., Rahimi-Vahed A. R., and Baharian Khoshkhou G., "A MultiObjective Scatter Search for a Dynamic Cell Formation Problem", Computers and Operations Research, Vol. 36, No. 3, pp. 777-794, 2009.

12. Ham I., Hitomi K., Teruhiko Y., "Group
Technology: Applications to Production Management", Kluwer and Nijhoff Publishing, 2012.

13. Javaid W., Tariq A., Hussain I., "A Comparison of a Standard Genetic Algorithm with a Hybrid Genetic Algorithm Applied to Cell Formation Problem", Advances in Mechanical Engineering, Vol. 6, 2014.

14. Zeb A., Khan M., Khan N.,Tariq A., Ali L., Azam F.," Hybridization of Simulated Annealing with Genetic Algorithm for Cell Formation Problem", International Journal of Advanced Manufacturing Technology, Vol. 85, No. 5-8, pp. 2243-2254, 2016.

15. Selim H. M., Askin R. G., Vakharia A. J., "Cell Formation in Group Technology: Review, Evaluation and Directions for Future Research", Computers and Industrial Engineering, Vol. 34, No. 1, pp. 3-20, 1998.

16. Irani S. A., Subramanian S., Allam Y. S., "Introduction to Cellular Manufacturing Systems", Handbook of Cellular Manufacturing Systems, John Wiley \& Sons, pp.1-23, USA, 1997.

17. Wemmerlöv U., Hyer N. L., "Cellular Manufacturing in the US Industry: A Survey of Users", International Journal of Productions Research, Vol. 27, No. 9, pp. 1511-1530, 1989.

18. Wu X., Chu C. H., Wang Y., Yue D., "Genetic Algorithms for Integrating Cell Formation with Machine Layout and Scheduling", Computers and Industrial Engineering, Vol. 53, No. 2, pp. 277-289, 2007.

19. Defersha F. M., Chen M., "A Linear Programming Embedded Genetic Algorithm for an Integrated Cell Formation and Lot Sizing Considering Product Quality", European Journal of Operations Research, Vol. 187, No. 1, pp. 4669, 2008.

20. Kioon S. A, Bulgak A. A., Bektas T., "Integrated Cellular Manufacturing Systems Design with Production Planning and Dynamic System Reconfiguration", European Journal of Operations Research, Vol. 192, No. 2, pp. 414 428, 2009.

21. Safaei N., Tavakkoli-Moghaddam R., "Integrated Multi-Period Cell Formation and Subcontracting Production Planning in Dynamic Cellular 
Manufacturing Systems", International Journal of Production Economics, Vol. 120, No. 2, pp. 301-314, 2009.

22. Rafiee K., Rabbani M., Rafiei H., Rahimi-Vahed, A., "A New Approach Towards Integrated Cell Formation and Inventory Lot Sizing in an Unreliable Cellular Manufacturing System", Appllied Mathematical Modelling, Vol. 35, No. 4, pp. 1810-1819, 2011.

23. Chang C. C., Wu T. H., Wu C. W., "An Efficient Approach to Determine Cell Formation, Cell Layout and Intracellular Machine Sequence in Cellular Manufacturing Systems", Computers and Industrial Engineering, Vol. 66, No. 2, pp. 438-450, 2013.

24. Nouri H., "Development of a Comprehensive Model and BFO Algorithm for a Dynamic Cellular Manufacturing System", Appllied Mathematical Modelling, Vol. 40, No. 2, pp. 1514-1531, 2016.

25. Fahmy S. A.,"Optimal Design and Scheduling of a Cellular Manufacturing System: An Experimental Study", Proceedings of the International Conference on Systems, Management and Cybernetics, IEEE, Budapest, Hungary, 2016.

26. Egilmez G., Singh S., Ozguner O., "Cell Formation in Cellular Manufacturing Systems under Uncertain Demand and Processing Times: A Stochastic Genetic Algorithm Approach", International Journal of Services and Operationas Management, Vol. 26, No. 2, 2017.

27. Khorasgani S., Ghaffari M., "Developing a Cellular Manufacturing Model Considering the Alternative Routes, Tool Assignment and Machine Reliability", Journal of Industrial Engineering International, Vol. 14, No. 3, pp.627-636, 2017.

28. Karoum B., Elbanani Y. B., "A Clonal Selection Algorithm for the Generalized Cell Formation Problem Considering Machine Reliability and Alternative Routings", Production Engineering Research and Development, Vol. 11, No. 4-5, pp. 545-556, 2017.

29. Hao C., Luan S., Kong J., "Simulation Analysis of an Integrated Model for a Dynamic Cellular Manufacturing System", AIP Conference Proceedings, Vol. 1839, No. 1, 2017.
30. Razazadeh, H., and Miab, A. K., "A Two-Layer Genetic Algorithm for The Design of a Reliable Cellular Manufacturing System", International Journal of Industrial Engineering Computations, Vol. 8, No. 3, pp. 315-332, 2017.

31. Gannon P., Suer G. A., "A Genetic Algorithm Approach for Loading Cells with Flow-Shop Configuration", Proceedings of the Eleventh International Conference on Management, Science and Engineering Management, pp. 559576, Kanazawa, Japan, 2017.

32. Hasan S. M., Baqai A. A., Butt S. U., Zaman U. K., "Product Family Formation Based on Complexity for Assembly Systems", International Journal of Advanced Manufacturing Technology, Vol. 95, No. 1-4, pp.569-585, 2018.

33. Arora P. K., Haleem A., Singh M. K., "Recent Development of Cellular Manufacturing Systems", Sadhana Indian Academy of Sciences, Vol. 38, No. 3, pp. 421-428, 2013.

34. Boctor F. F., "A Linear Formulation of the Machine-Part Cell Formation Problem", International Journal of Production Research, Vol. 29, No. 2, pp. 343-356, 1991.

35. King J. R., Nakornchai V., "Machine-component Group Formation in Group Technology: Review and Extension", International Journal of Production Research, Vol. 20, No. 2, pp.117133, 1982.

36. Waghodekar P. H., Sahu S., "MachineComponent Cell Formation in Group Technology: MACE", International Journal of Production Research, Vol. 22, No. 6, pp.937948, 1984.

37. Seifoddini H., "A Note on the Similarity Coefficient Method and the Problem of Improper Machine Assignment in Group Technology Applications", International Journal of Production Research, Vol. 27, No. 7, pp.11611165, 1989.

38. Kusiak A., Chow M., "Similarity Coefficient Algorithms for Solving the Group Technology Problem", International Journal of Production Research, Vol. 30, No. 11, pp. 2633-2646,1992.

39. Kusiak A., Chow W. S.," Efficient Solving of the Group Technology Problem", Journal of Manufacturing Systems, Vol. 6, No. 2, pp. 117- 
124, 1987.

40. Chandrasekharan M. P., Rajagopalan R., "An Ideal Seed Non-Hierarchical Clustering Algorithm for Cellular Manufacturing", International Journal of Production Research, Vol. 24, No. 2, pp. 451-463, 1986.

41. Mosier C., Taube L., "Weighted Similarity Measure Heuristics for the Group Technology Machine Clustering Problem", Omega, Vol. 13, No. 6, pp. 577-579, 1985.

42. Chan H.M., Milner D. A., "Direct Clustering Algorithm for Group Formation in Cellular Manufacturing", Journal of Manufacturing Systems, Vol. 1, No. 1, pp. 65-75, 1982.

43. Askin R. G., Subramanian S. P., "A Cost-Based Heuristic for Group Technology Configuration", International Journal of Production Research, Vol. 25, No. 1, pp.101-113, 1987.

44. Stanfel L. E., "Machine Clustering for Economic Production", Engineering Costs and Production Economics, Vol. 9, No. 1-3, pp. 73-81, 1985.

45. McCormick W. T., Schweitzer P. J., White T. W., "Problem Decomposition and Data Reorganization by a Clustering Technique", Operations Research, Vol. 20, No.5, pp. 9931009, 1972.

46. Srinlvasan G., Narendran T. T., Mahadevan B., "An Assignment Model for the Part-Families Problem in Group Technology", International Journal of Production Research, Vol. 28, No.1, pp. 145-152, 1990.

47. King J.R.,"Machine-Component Group Formation in Group Technology", OMEGA:The International Journal of Management Science, Vol. 8, No. 2, pp.193-199, 1980.

48. Kumar K. R., Kusiak A., Vannelli A., "Grouping of Parts and Components in Flexible Manufacturing Systems", European Journal of Operations Research, Vol. 24, No. 3, pp. 387397, 1986.

49. Carrie A. S., " Numerical Taxonomy Applied to Group Technology and Plant Layout", International Journal of Production Research, Vol. 11, No. 4, pp. 399-416, 1973.

50. Boe W. J., Cheng C. H., "A Close Neighbour Algorithm for Designing Cellular Manufacturing Systems", International Journal of Production Research, Vol. 29, No. 10, pp. 2097-2116, 1991.
51. Chandrasekharan M. P., Rajagopalan R., "Groupability: An Analysis of the Properties of Binary Data Matrices for Group Technology", International Journal of Production Research, Vol. 27, No. 6, pp.1035-1052, 1989.

52. Solangi S. A., Hakro D. N., Memon M., Khoumbati K. R., Jalbani A. H., "Optimization by Genetic Algorithm in Wireless Sensor Networks Utilizing Multiple Sinks", Mehran University Research Journal of Engineering and Technology, Vol. 38, No. 4, pp. 923-934, 2019.

53. Tariq A., "Operational Design of a Cellular Manufacturing System", Lap Lambert Academic Publishing, Germany, 2014. 